\title{
Involving service users in sexual health service development
}

\author{
Paula Baraitser, Vikki Pearce, Geraldine Blake, Kirsty Collander-Brown, Andrew Ridley
}

\begin{abstract}
Objectives The study objectives were to document users' experience of family planning and genitourinary medicine clinics and young people's services working within the time constraints of rapid service development and maximising the utility of this data for service improvement.

Methods A total of 93 users of family planning and genitourinary medicine services participated in one of 13 facilitated discussion groups. Some $61 \%$ of the sample were women, $64 \%$ were aged over 25 years and $47 \%$ were Black Caribbean or Black African. The clinic journey was drawn on a wall covered with paper and participants added their comments during the discussion.

Results Users had similar concerns across the three service types. Users perceived some receptionists and clinicians as unfriendly and judgmental and described others providing a quality service often under difficult conditions. Reception was insufficiently confidential, waiting environments uncomfortable, waiting times long and more information was needed throughout service use.

Conclusions Those elements of sexual health services known to be a source of dissatisfaction among young people may also be a problem for older service users and are experienced across different types of sexual health service. This preliminary study demonstrates the feasibility and acceptability of focus group evaluations of sexual health services. This approach generates qualitative data from relatively large numbers of users within a timescale consistent with service development.
\end{abstract}

J Fam Plann Reprod Health Care 2005; 31(4): 281-284 (Accepted 28 July 2005)

\section{Key message points \\ - Sexual health service users from all types of service reported that reception was insufficiently confidential, waiting environments uncomfortable, waiting times long, clinicians often unfriendly and judgmental, and insufficient information provided. \\ - A method of collecting qualitative data from large numbers of service users within a timescale consistent with service development is described.}

Lewisham Primary Care Trust, London, UK

Paula Baraitser, MD, MFFP, Specialist Registrar in Public Health Medicine

Lambeth and Southwark Sexual Health Modernisation

Programme, London, UK

Vikki Pearce, BSc, PGDip, Project Manager

Gap Research, London, UK

Geraldine Blake, PGDip, Director

Kirsty Collander-Brown, BA, Research Co-ordinator

Guys and St Thomas' NHS Foundation Trust, Guys Hospital, London, UK

Andrew Ridley, MBA, MA, Project Director, Lambeth and Southwark Modernisation Initiative

Correspondence to: Dr Paula Baraitser, Lambeth and Southwark Sexual Health Modernisation Programme, Masters House,

4 Dugard Way, London SE11 4TH, UK.

E-mail: paulab@smithg3.demon.co.uk

\section{Background}

England has high rates of sexually transmitted infection (STI) and unintended pregnancy. Between 2001 and 2002, the diagnosis of genital chlamydia in genitourinary medicine (GUM) clinics increased by $14 \% 1$ and abortion rates among women aged 20-24 years were 30 per 1000 in $2002 .^{2}$ Increasing rates of sexual ill-health have led to an interest in strategies to develop sexual health services. ${ }^{3}$

The UK Government advocates involving users in health service improvement to develop a 'patient-centred' National Health Service (NHS). ${ }^{4}$ This information is more likely to inform service development if it answers questions relevant to service providers within the timescale for improvement. ${ }^{5}$

Modernisation work within the NHS has employed methods such as focus groups and patient diaries to inform service development. 6 These methods are chosen because they collect detailed data quickly in a form that can influence service improvement. Learning from this work is infrequently referenced in academic journals and is therefore not shared. This may because of concerns about the rigour and generalisability of data collected in this way. ${ }^{5}$ However, service evaluations may contain timely and relevant information for sexual health service providers if methodological issues and their implications are discussed. Exclusion of this work from the published literature may inhibit the spread of ideas for service improvement. This paper is an example of user involvement in service development within the practical constraints of a sexual health modernisation programme. The learning is relevant and its limitations are discussed.

The services studied were five large sexual health services (used by 3000 clients per week) in two inner London boroughs with very high rates of sexual ill-health. Provider representatives from all services supported and participated in the project and are redesigning service delivery structures and improving services, partly on the basis of the data presented here.

\section{Evaluation questions}

1. Can focus groups be used to collect qualitative data on user satisfaction from large numbers of sexual health service users quickly enough to influence service development?

2. Which elements of sexual health services in the area studied need improvement?

\section{Methodology}

Qualitative and quantitative approaches to enquiry are traditionally described as mutually exclusive (though sometimes complimentary) and based on conflicting perspectives of the social world. However, a focus on the divisions between these approaches obscures the strengths of each and misses opportunities for learning across research disciplines. ${ }^{7-10}$ This paper draws on concepts from both quantitative and qualitative research in an effort to meet the information needs and timescales of service providers and commissioners. For example, it uses simple counting in qualitative data to 'avoid(ing) anecdotalism', 11 and to show the reader as much of the data as possible to demonstrate that the writer has not relied excessively on rare events while excluding more common ones. ${ }^{12}$ 


\section{ARTICLE}

Table 1 Focus groups in which comments to support key findings were recorded

\begin{tabular}{lcccc}
\hline Hypothesis & FP & GU & YP & Total \\
\hline $\begin{array}{l}\text { Some receptionists are perceived as unfriendly } \\
\text { Reception areas are insufficiently confidential }\end{array}$ & Yes & Yes & Yes & $8 / 13$ \\
$\begin{array}{l}\text { Waiting environments are uncomfortable or } \\
\text { have insufficient facilities }\end{array}$ & Yes & Yes & Yes & $9 / 13$ \\
$\begin{array}{l}\text { Waiting time is too long } \\
\begin{array}{l}\text { Some clinicians are perceived as unfriendly/ } \\
\text { judgmental }\end{array}\end{array}$ & Yes & Yes & Yes & $11 / 13$ \\
$\begin{array}{l}\text { More information is needed } \\
\text { Yos }\end{array}$ & Yes & Yes & Yes & $10 / 13$ \\
\end{tabular}

FP, groups of family planning service users; GU, groups of genitourinary medicine service users; YP, groups of users of young people's services; Total, total number of groups recording data to support this finding.

Reporting single quotes from individual users may not stimulate service improvement as providers cannot tell whether they reflect the experience of many. Quantitative data are a powerful stimulus for change but accurate quantitative data on experience of health service use are difficult to record (see below).

The usefulness of quantitative data collection strategies to document experience of health services is controversial. User satisfaction surveys are known to produce high levels of reported satisfaction even where there is clear evidence of dissatisfaction from qualitative interviews with the same users. ${ }^{13-15}$ Users are reluctant to criticise health professionals on whom they depend for care, and this situation is exacerbated when they experience their condition as stigmatising. Qualitative interviews provide a safer environment for users to comment on health services but are feasible for small numbers of service users only.

Focus groups generate qualitative data from substantial numbers of respondents in an informal setting. The group setting may empower users to describe negative experiences, particularly if these are shared by others in the group. ${ }^{16}$ Traditionally, focus group discussions are taperecorded and the resulting transcripts subjected to a formal qualitative analysis. In this study the researcher(s) identified the important points from the data. An alternative approach was used here where the participants decided which points they felt were most important and recorded these themselves. This had three advantages. First, the involvement of users in the initial stages of analysis; second, decreasing the volume of material generated to facilitate timely analysis; and third, the production of discrete 'parcels' of data (namely the individual comments) that could be counted.

The importance of considering the audience for data collection is clearly acknowledged within the health service evaluation literature but receives less attention in academic journals. The usefulness of the data collected to service providers and managers was a key consideration underpinning the choice of methods in this study.

\section{Methods}

Service users were recruited by pairs of researchers (one male and one female) in clinic waiting rooms. The researchers received training on participatory research methods and ethical and confidentiality issues that might arise during recruitment. One researcher facilitated a short discussion on waiting room environments to demonstrate the planned data collection method and show those waiting that they have ideas and experiences to contribute. The second researcher distributed information sheets inviting those present to attend an evening or Saturday workshop and answered questions. Ten recruitment sessions, run at different times, at family planning and GUM clinics in the area generated a database of 200 potential participants.
Prior to each workshop all those on the database who had not yet participated received a written invitation followed by one or two telephone calls to confirm attendance and answer questions. Participants received an honorarium of $£ 30$ and childcare costs if required.

The workshops were held away from clinical services: one in a community Internet café (at a time when it was closed to the public) and two in an administrative building not identifiable as part of the health service. Participants were assigned to facilitated, service-specific focus groups (family planning or GUM) comprising 3-18 participants. Each group described the stages of a clinic visit and comments were recorded by the facilitator on a wall covered with paper. For each stage, participants discussed the following questions:

- What happened at this stage of the clinic visit?

- How long did it take?

- How did you feel about it?

- What was good about it?

- What was bad about it?

- How could it be improved?

The same researchers who had recruited for this study also facilitated the focus groups. In groups where the majority of participants were of one sex, a facilitator of the same sex was chosen. The facilitators were local people, working with a community-based organisation specialising in consultation on public services. They received training on confidentiality and the potential sensitivity of information relating to the use of sexual health services and practised the exercise as a group themselves.

A novel approach to recording the discussion was adopted where the key points raised were recorded by participants themselves on Post-it ${ }^{\circledR}$ Notes and added to the diagram showing the stages of the clinic visit. The facilitators were briefed to ensure that all views within the group were heard and recorded. As participants expressed their views, facilitators would encourage them to write them down and add them to the wall chart. If there was disagreement they would encourage all those involved to record their different views. After the session all the Post-it Notes comments for each group were transcribed. The session was evaluated with an anonymous form. Ethical approval was obtained from the local ethics committee.

\section{Analysis}

The transcripts of the Post-it Notes for each group were read and re-read by one of the authors (P.B.) to identify key themes. Participants raised five main issues that accounted for $59 \%$ of the comments and were raised in at least $60 \%$ of the groups. All the comments related to these general themes were cut and pasted into a single document and also divided according to the group where they were recorded. A coding framework was developed for each general theme to describe the comments it contained. For example, codes for the comments on waiting room environment included seating, refreshments, confidentiality and facilities for children. A summary statement to describe the comments relating to each of the codes was developed and the lists of individual comments systematically checked for data to support or contradict this summary. Data that were inconsistent with the summary led to their modification or rejection. Where the comments suggest different viewpoints on the same topic this disagreement is described. The summaries generated from the pooled data were then checked against the group-specific data to see which groups had generated data to support them.

This approach to analysis aims to summarise a large dataset, identify those elements of local services requiring improvement and present them to service providers and 
commissioners. It focuses on those elements of user's experiences that are common to many users and across services, in this way identifying the essential elements of a service improvement programme.

\section{Results}

\section{Sample}

A total of 93 service users ( 32 men and 61 women) of the 200 recruited participated in focus groups. Some $64 \%$ of the sample were aged over 25 years and $47 \%$ were Black Caribbean or Black African. The recruiters reported on their evaluation forms that black and ethnic minority service users were more likely to agree to participate and that women were more likely to be recruited than men. This is consistent with a comparison of our sample with the population of Lambeth and Southwark (24\% population Black/Black British: African or Caribbean). ${ }^{17}$ The Black African and Caribbean population in the study area is at particularly high risk of sexual ill-health. ${ }^{18}$

The data collection, analysis and presentation of results to clinicians and managers took less than 6 months.

\section{General}

Participants made 951 Post-it Notes comments on their experience of sexual health service use. One comment does not express the views of one individual but may be the view of a number of people who delegated its documentation. The discussion was wide ranging with many topics raised by single groups or individuals. This paper focuses on the data on the following five themes that were consistently identified as important (59\% of the comments):

- Staff attitudes within the clinical consultation (133 comments; 14\%)

- Confidentiality and staff attitudes at reception (129 comments; $13.6 \%$ )

- The quality of waiting room environments (119 comments; $12.5 \%$ )

- The length of waiting time (92 comments; $9.6 \%$ )

- The need for more information at all stages of the clinic visit (92 comments; $9.6 \%$ ).

Support for the key findings was consistent across the different focus groups (Table 1), that is consistent across the different services being discussed.

\section{Reception}

A total of 121 comments on reception were recorded of which the majority (72 comments; 60\%) were negative. Experience at reception was mixed, with receptionists reported as both rude (23 comments, 8/13 groups) and friendly ( 21 comments). Some participants reported very negative experiences: "stripped and humiliated when initially approached reception" and "not nice being shouted at". Others were pleased: "very nice people and comfortable treating". Users emphasised the importance of the receptionist's role: "needs a range of skills - make people more comfortable/info/counselling" and the difficult nature of their job: "understaffed which made staff become impatient". There was consensus that reception was insufficiently confidential (32 comments, 9/13 groups). Only two comments report it as confidential, and there was a clear message that reception should be separate from the waiting room where "there are so many people listening".

\section{Waiting}

Of the 122 comments on the waiting environment, 27 requested entertainment of sufficient quality, 12 facilities for children and 16 refreshments at a reasonable price. Entertainment is important not just to pass the time but to reduce anxiety. All of the 11 comments on waiting room atmosphere were negative, suggesting that it exacerbates pre-existing anxiety, a situation made worse by overcrowding (19 comments). "Then go to the little room, sit down, everyone looks at one another's faces." "Not enough chairs, people have to stand in the waiting room."

Of the 92 comments on waiting time, 45 indicated that the waiting time is too long and an additional 12 reported a waiting time of more than 2 hours. The nine comments on maximum acceptable waiting times gave figures of 30 minutes to 2.5 hours. Four report that the waiting time was acceptable, with two describing it as expected or acceptable "for a free service". Waiting generates anxiety; some people leave and some are reluctant to return. "Saw people walk in - see the waiting room - and walk out. More walked out after waiting." "Back to waiting room: felt gutted at having to wait again." "Became more nervous than when I started." "Think NEVER AGAIN - waiting time puts you off."

\section{Clinical consultation}

Of the 111 comments on the clinical consultation, 19 comments were positive about staff attitudes and 41 were negative. The most important aspect from a user's perspective was the extent to which clinicians were judgmental, patronising or intimidating. "Bad experience makes you feel wrong for being there and interrogated." "Need to know the risks but don't want to feel judgedsometimes I lie." "Nurse talked about 'shouldn't have' and 'guilty'." "Talk down to you makes you feel uncomfortable." Those who were positive about staff attitudes were relieved that staff were not judgmental. "Don't put you down, encourage you, don't kill off your self-esteem". Fifteen comments requested a choice of male or female clinician.

\section{More information at all stages of the process}

Users requested more information at all stages of their visit to sexual health services (93 comments). They wanted more information before using the service, at reception during the clinical consultation, or with the results. They requested more information about the clinic and its organisation, general sexual health and their specific condition.

\section{Feedback on the process from service users}

Eighty-six focus group participants completed an evaluation form (a 92.5\% response rate). Eighty (93\%) reported that they had "said the things they wanted to say" in the workshops and six felt they had not, mainly because they found the group setting for discussion inhibiting. Seventy-nine (92\%) participants reported that it was an enjoyable way to spend 3.5 hours and none said it was not. Participants reported that they had had a "really good time", "meeting new people" and pleased to have the chance to "voice some strong opinions I have". They valued it because "payment is offered and refreshments is given and everyone gets to share their opinion".

\section{Discussion}

A significant body of work published in the UK in the 1980 s and 1990s suggested that reception, waiting times and environments, staff attitudes and lack of information were important determinants of dissatisfaction among sexual health service users in the UK. ${ }^{19-23}$. This work focused almost exclusively on the experience of young people and there was very little comparison between different types of services. The work described in this paper suggests that:

- Those issues identified as important by young people 


\section{ARTICLE}

are similarly important for older users (64\% of our sample was aged over 25 years).

- Key elements of users' experience are consistent between different services.

These findings are important because the focus of much of sexual health service improvement policy has been on services for the under- $25 \mathrm{~s}^{24,25}$ and less attention has been paid to the similar problems experienced by older service users.

The consistency of user's experience across services that look different to clinicians, managers and commissioners was unexpected. These services have different staff, locations and clinical and administrative protocols. Our data suggest that there may be common elements of sexual health service provision within family planning, GUM and specialist young people's services that are sources of user dissatisfaction.

Public and service user involvement mechanisms for facilitating feedback have an important role to play in improving the quality of services. ${ }^{26}$ The evaluation described is unusual in that it generated qualitative data from a large sample. Participants identified the important elements of their contribution and this simplified analysis but generated a list of comments rather than the transcript of a conversation and therefore the context for the comments was lost. The analysis is based on the assumption that the number of comments on each theme reflects the number of participants holding that view. Although the feedback from the focus group facilitators suggested that this was the case, this assumption is untested. The use of simple counting to analyse qualitative data showed the extent to which each theme was generalisable within our sample of users. We felt that this was important for an audience of service providers and commissioners who may find it difficult to plan service improvement on the basis of detailed information on the experience of very small numbers of service users. Although discussion of sexual health issues often generates discomfort, users report that the relaxed atmosphere in the focus groups enabled them to discuss their experience of service use openly and with little embarrassment. In this sense the research was empowering and not extractive. Participants enjoyed their experience and were pleased that their time was valued and remunerated.

The data have important limitations. Reporting of quantitative data from qualitative discussions raises questions about the representativeness of the sample recruited and the subsample that participated.

User consultation requires significant resources. Of the 200 users recruited in clinic waiting rooms, 93 attended a workshop despite intensive follow-up (one letter and two telephone calls), a $£ 30$ honorarium, refreshments and provision for childcare.

The standards expected by the users in this study are consistent with those developed by the Medical Foundation for AIDS and Sexual Health in consultation with professionals and raises questions about strategies for meeting them. This study has contributed to a programme of sexual health service development that will include:

- A slot system to reduce waiting times

- A mystery shopper programme to provide servicespecific feedback

- User involvement in receptionist training

- Strategies to manage demand including a focus on selfmanagement in sexual health

- Development of sexual health services in generalist settings including community pharmacies and general practice.

\section{Conclusions}

This small, preliminary study in an ethnically diverse inner city area has demonstrated the feasibility and acceptability of recruiting service users to focus group evaluations of sexual health services. This approach, which generates qualitative data from large numbers of users within a timescale consistent with service development, could be used more widely to identify users' perspectives on priorities for improvement.

\section{Statements on funding and competing interests}

Funding. This study was funded by the Charitable Foundation of Guys and St Thomas's Hospital as part of their funding for the Lambeth and Southwark Sexual Health Modernisation Programme.

Competing interests. Paula Baraitser, Vikki Pearce and Andrew Ridley all work for the Lambeth and Southwark Sexual Health Modernisation Programme that is working to redesign sexual health services in the area. Geraldine Blake and Kirsty Collander-Brown have no competing interests to declare.

References

1 Renewing the focus: the 2002 annual report on STIs and HIV in the UK. CDR Weekly 2003; 13(48). http://www.hpa.org.uk/cdr/PDFfiles/ 2003/cdr4803 pdf [Accessed 24 May 2005].

2 Department of Health. Abortion Statistics England and Wales, 2002. London, UK: Department of Health, 2003. http://www.dh.gov.uk/ assetRoot/04/08/00/59/04080059.pdf [Accessed 24 May 2005].

3 Independent Advisory Group for Sexual Health and HIV. Annual Report 2003/4. London, UK: Department of Health, 2005. http://www.dh.gov.uk/assetRoot/04/09/03/25/04090325.pdf [Accessed 24 May 2005].

4 Department of Health. The NHS Plan. Norwich, UK: The Stationery Office, 2000.

5 The Health Foundation and The Nuffield Trust. Increasing the Impact of Health Services Research on Health Service Improvement. London, UK: The Health Foundation and The Nuffield Trust, 2003. http://www.health.org.uk/documents/HSRreport.pdf [Accessed 24 May 2005]

6 NHS Modernisation Agency. Improvement Leaders' Guide to Involving Patients and Carers, 2002. http://www.modern.nhs.uk/ improvementguides/reading/involving_patients.pdf [Accessed 24 May 2005]

7 Bowling A. Research Methods in Health: Investigating Health and Health Services. Buckingham, UK: Open University, 1997; 114,

8 Seale C. The Quality of Qualitative Research. London, UK: Sage, 1999; 31 .

9 Silverman D. Interpreting Qualitative Data: Methods for Analysing Talk, Text and Interaction. London, UK: Sage, 1993; 203-204.

10 Murphy E, Dingwall R, Greatbatch D, Parker S, Watson P. Qualitative research methods in health technology assessment: a review of the literature. Health Technol Assess 1998; 2(16): iii-ix, 1-274.

11 Silverman D. Interpreting Oualitative Data: Methods for Analysing Talk, Text and Interaction. London, Sage, 1993:163.

12 Seale C. The Quality of Qualitative Research. London, Sage, 1999:128.

13 Dougall A, Russell A, Rubin G, Ling J. Rethinking patient satisfaction: patient experiences of an open access flexible sigmoidoscopy service. Soc Sci Med 2000; 50: 53-62.

14 Avis M, Bond M, Arthur A. Questioning patient satisfaction: an empirical investigation in two outpatient clinics. Soc Sci Med 1997; 44: 85-92.

15 Sitzia J, Wood N. Patient satisfaction: a review of issues and concepts. Soc Sci Med 1997; 45: 1829-1843.

16 Bowling A. Research Methods in Health: Investigating Health and Health Services. Buckingham, UK: Open University, 1997; 352.

7 http://www.statistics.gov.uk.

18 Low N, Daker White G, Barlow D, Pozniac A. Gonorrhoea in inner London: results of a cross sectional study. BMJ 1997; 314: 1719.

9 Allen I. Family Planning and Pregnancy Counselling Projects for Young People. London, UK: Policy Studies Institute, 1991.

20 Wardle S, Wright P. Family planning services - the needs of young people. A report from Mid Staffordshire. Br J Fam Plann 1993; 19. $158-160$.

21 Clements S. Young people's sexual health in Southeast Hampshire. Final Report. Centre for Sexual Health Research, Faculty of Social Sciences, University of Southampton, Southampton, UK, 1999.

22 Smith A. Young people's contraception and sexual health: report of a local needs assessment in Staveley, North Derbyshire. J Fam Plann Reprod Health Care 2001; 27: 29-33.

23 Harden A, Ogden J. Sixteen to nineteen year olds' use of, and beliefs about, contraceptive services. Br J Fam Plann 1999; 24: 141-144.

24 Social Exclusion Unit. Teenage Pregnancy. London, UK: HMSO, 1999.

25 Department of Health. The National Strategy for Sexual Health and HIV. London, UK: HMSO, 2001.

26 Medical Foundation for AIDS and Sexual Health. Recommended Standards for Sexual Health Services. London, UK: Medical Foundation for AIDS and Sexual Health, 2005. http://www.medfash. org.uk/publications/current.html [Accessed 24 May 2005]. 